\title{
AC 2008-854: A MOBILE STUDIO EXPERIENCE OF EXPERIENTIAL LEARNING IN ELECTRICAL ENGINEERING CLASS
}

\section{Charles Kim, Howard University}

Charles Kim received a Ph.D. degree in Electrical Engineering from Texas A\&M University in 1989. From 1990 to 1994 he was a post-doctoral research associate and, later, a research faculty member at Texas A\&M University. From 1994 to 1998, he was an assistant professor at the University of Suwon. Since 1999, he is with Department of Electrical Engineering at Howard University. Dr. Kim's research interests include PLC home networking, embedded computing, Internet-based decision-making, and intelligent systems application. Dr. Kim is also active in application and assessment of technology in engineering education.

\section{Mohamed Chouikha, Howard University}

Mohamed Chouikha received a Ph.D. degree in Electrical Engineering from the University of Colorado in Boulder in 1988. Since 1988, he has been with Department of Electrical Engineering at Howard University. Since 2000, he has been serving as the Chair of the EE Department. Dr. Chouikha's research interests include Multimedia Signal Processing and Communications, Wireless Communications, and Home-networking. Dr. Chouika is the prime mover of the mobile studio inception and expansion into Howard University.

\section{Veronica Thomas, Howard University}

Veronica G. Thomas received a Ph.D. degree in Social Psychology from Howard University in 1982. She is currently a Professor within the Department of Human Development and Psychoeducational Studies and Senior Research Associate with the Capstone Institute, both at Howard University. Dr. Thomas' research interests include culturally responsive evaluations and the educational and socio-emotional outcomes of students of color. Dr. Thomas has collaborated with the Department of Electrical Engineering in planning and implementing evaluation studies. 


\section{Mobile Studio Experience of Experiential Learning in Electrical Engineering Class}

\section{Introduction}

All core courses in Electrical and Computer Engineering at Howard University and, at certain extent, in most engineering and science disciplines everywhere, are each taught by a combination of lecture and laboratory. The idea behind the lecture-lab combination is to help bridge the gap between the classroom knowledge of theory and the practical aspect in real world. The good idea, however, has failed to produce the necessary practice and intended result. Lecture and lab are seldom taught in the same class and, therefore, different topics are covered in two separate classes. Often, lecture and lab are taught by different instructors. Consequently, the intended learning reinforcement by active experimentation of lectured abstract concept is not realized. Theories and applications have been divided; simulations and implementations, alienated. Great is the need of lecture/lab hybrid class that unifies two components together, and equally high is the demand of experiential learning in which introduction of theories and their experiences are instant and dynamic. Behind this persistent disunity between lecture and lab, there is a practical reason: the daunting task of bringing lab into class. Traditional labs are equipped with workbenches and expensive bulky instruments.

Technology development and miniaturized packaging, however, enabled to produce palm-sized instrumentation interface boards which can replace most of the Electrical Engineering lab equipment and thus can bring lab into class. A computer with the interface can become a portable lab or Mobile Studio. Mobile Studio is philosophy and pedagogy which intends to bring laboratory into classroom with a mobile, portable set of computer and scope software provided with similar functionality to that of the traditional laboratory equipment. The Mobile Studio enables the experiential learning for students in classroom through instant experimentation and verification of the classroom knowledge by producing waveforms, measuring and recording signals, and analyzing recorded data. The Mobile Studio class at Howard University made a great impact in learning enhancement of for the students.

The Department of Electrical and Computer Engineering at Howard University launched the Mobile Studio classes in 2005. This paper details the experience of the Mobile Studio classes, including the hardware implementation and the throwing of students into the new environment, and discusses the impact of the Mobile Studio in the classroom environment in two aspects: the students' attitudes toward the new learning environment and the students' learning in core knowledge and concepts.

The paper is organized as follows. In the next section, we discuss about the pedagogy of Mobile Studio in regard to experiential learning and the effect on learning and faculty pedagogical practices. In section III, the experience of the mobile studio is described. The lengthy section IV reports the evaluation results of the survey for acceptance and learning enhancement along with comments on the problems and difficulties, and offers suggestions for smooth transition from traditional, split lecture and lab courses into Mobile Studio-based lecture/lab hybrid courses for experiential learning practice. Conclusions are drawn in section V. 


\section{Mobile Studio Concept}

Studio teaching, adopted normally in arts and architecture for their distinctive feature of design studio, now grew into science and engineering as a model for student-centered learning environment where hands-on experimentation is integrated with concept and application. The studio teaching in science and engineering, through the increased interaction from peer-to-peer discussions to one-onone exchanges between student and instructor, focuses on the following targets: integration of fundamental concepts and practice skills; learning by discovery; and combination of analysis, simulation, and experiment ${ }^{1}$. Creation of a studio teaching classroom, however, comes with a cost which, in small engineering programs, discourages its adoption. Under squeezed minimal-level lab budget, the high cost involved in designing a classroom for studio teaching or converting current laboratory into studio is the main deterrent of adopting the studio teaching.

Then, in 2004, Don Millard at Rensselaer Polytechnic Institute (RPI) solved the cost problem. His "Mobile Studio" project developed a hardware/software interface which, when connected to computer via USB cable, provides similar functionality to that of the laboratory equipment currently associated with an instrumented studio classroom ${ }^{2}$. The first generation Mobile Studio was realized by a tablet PC, and instrumentation interface implemented on a breadboard, and graphic display software as shown in Fig. 1. The instrumentation interface reads data from and sends signals to the student circuit made in the open space of the interface board. The graphic display software allows students, by tapping icons and clicking buttons, to measure and display data and to generate signals. With access to wireless internet for class materials, the portable set replaces the studio classroom and, importantly, heavy lab equipment. The lean transformation provides mobile learning environments that are no longer limited by facility and equipment issues.

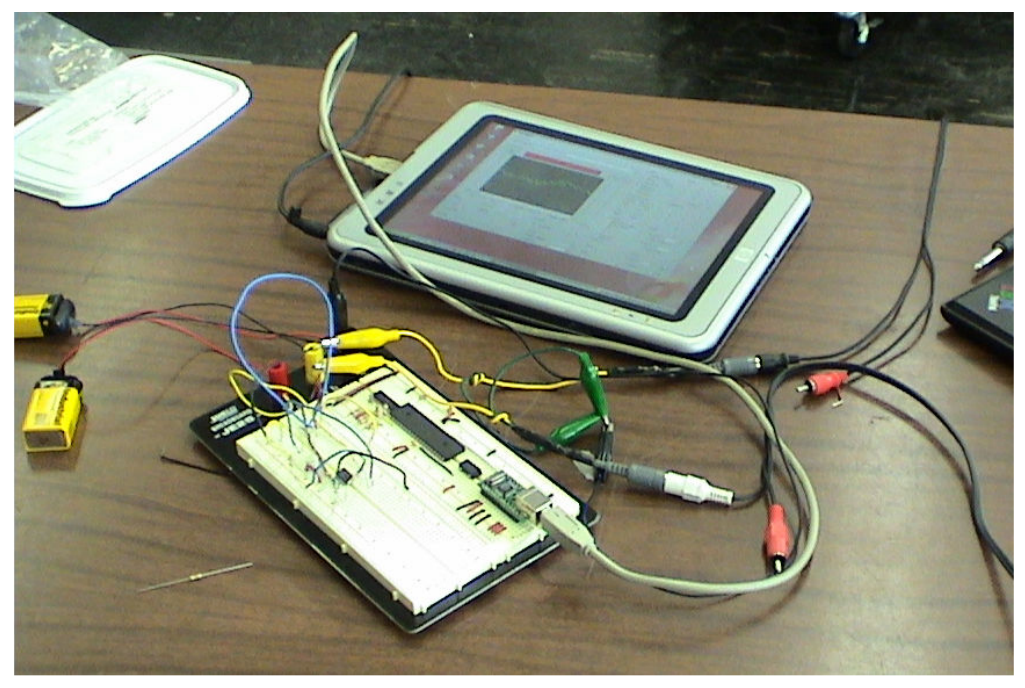

Fig.1. The first generation mobile studio in which the instrumentation interface is realized on a breadboard.

The Mobile Studio now brings lab into class, and enables "learning by doing and engagement" which increases knowledge retention rate. According to the Learning Pyramid chart ${ }^{3}$, which rates the average retention for various methods of teaching, lecture alone, the top of the pyramid, achieves 
an average retention rate of 5\%. At the bottom of the chart, the "practice by doing" and "teach others/immediate use" methods achieve an average retention rate of $75 \%$ and $90 \%$, respectively. The Mobile Studio improves the knowledge retention rate by instant experience of theory and experimentation of the theory.

The experience of "learning by doing" of Mobile Studio also makes possible to practice experiential leaning, a process by which students reflect on what they learned and, from the reflection, new learning emerges ${ }^{4}$. Starting from the abstract concept of theory and model presented, students develop experiments gain concrete experience of the theory by the measurement and observation of the experiment. Analysis of the result and discussion with other students enable students to think over what they learned and to apply the theory in practical application. At the end of the process, students' understanding of the theory is much enhanced and retained much longer. The benefit of experiential learning further expands to the real world success for students. Experiential learning in interdisciplinary projects program is reported to increase readiness for self-directed learning and lifelong learning by which the real-world success for engineers is often measured ${ }^{5}$. The Mobile Studio can turn any room into an experiential classroom.

Considered in the impact, the Mobile Studio is not just a new technology applied to engineering education: it is effective learning pedagogy and an economical practice of the pedagogy. Mobile Studio enables resource-limited institutions to establish mobile lab-classrooms in any space on campus. Also, lab component teaching in online courses, which has been neglected due to the constraints, can benefit from the mobile studio: remote students now can get the hands-on experience of experimentation.

From the early stage of the mobile laboratory concept, Howard University's Electrical and Computer Engineering has partnered with Millard and, upon receipt of the necessary hardware and software, launched Mobile Studio in the core course teaching. The mobile studio enabled and encouraged "hands-on" exploration of engineering principles that has been restricted to specific laboratory facilities. The mobile studio we report in the paper is centered on the experiences in two core courses in the department at Howard University in 2005 spring and fall semesters.

\section{Experience with Mobile Studio Classes}

In spring 2005, the department tested the mobile studio class for the Network Analysis course. The Network Analysis is the basic circuit theory course that covers principles of circuit laws and behavior of circuits in time and frequency domain under different values of the circuit components of resistor, inductor, and capacitor. Transformation technique for frequency analysis and analysis of frequency selective circuits are also covered in the course.

Started with demonstration of the mobile studio as an introduction of new learning environment, the class held four mobile studio classes. The main reason of holding fewer than planned number of mobile classes was that, first, it was the first experience for both the teacher and the students and, second, the materials of the class thought to be enough were not quite satisfactory for some of the experimentations. The teacher needed more time in the preparation for the seamless application of the technology and for the materials of experiments. Here we introduce one exciting mobile class enjoyed by the teacher and the students. 
The objective of the mobile studio class was to understand the roles of the three components of R, L, and $\mathrm{C}$ in transient circuit behavior when a pulsed DC source was applied to the circuit. In the theory part, the response of second order differential equation for voltage across an element was derived and the oscillation behaviors were explained in terms of the values of R, L, and C. This would be all for a lecture only class. In the mobile studio teaching, we could test RLC circuit and measure the voltage across each element and see the waveform. The more exciting thing was that we applied a reverse approach: instead of asking students to calculate or guess the transient response of an RLC circuit with given component values, which is forward approach, we asked students to guess the resistance of the potentiometer used as $\mathrm{R}$, with fixed $\mathrm{L}$ and $\mathrm{C}$ values, after displaying the measured waveform across $\mathrm{R}$. This reverse approach provided students a chance to see the transient response problem in very different perspective: a perspective of the roles and actins of each component plays in a circuit. This experience of experimentation made the theory jump out of the circuit and impacted the students greatly in appreciation of the theory and joy of experiment, which no doubt would last long.

At the end of the spring semester, we conducted a simple survey via email of the acceptance of the mobile studio. We had some general idea that learning was enhanced, but with only four experiences, we decided to ask only the response to the mobile studio itself. The response was very encouraging and exciting. The details of the spring semester survey are described in the next section.

In summer 2005, we received the HP grant for technology in higher education for the mobile studio application. The grant provided us 21 Compaq tablet PCs and a wireless access point, a network printer, and an LCD projector. Also, a new palm-sized instrumentation board (see Fig. 2) was developed from RPI and immediately shipped to Howard University for use.

In fall 2005, the Electronics class was selected to apply the Mobile Studio with HP tablet PCs and the second generation instrumentation board. Electronics class, for junior students, focuses on the electronic elements and their behaviors in a circuit and covers diodes, transistors, and their applications. More mobile studio classes were held this semester due to the experience of the previous semester and more preparation time during the summer. The most exciting mobile studio class was to design and build a cellular phone audio receiver. Using the tablet PC, each student first simulated a circuit using PSPICE and Mentor Graphics, further analyzed the simulated circuit using Microsoft Excel to extract device and circuit parameters, and implemented the circuit in the breadboard. Then circuit was tested and displayed, and gave students, instantaneously, the feel and sound of the circuit they designed.

At the end of the semester, we conducted a class survey on the students' grade changes compared with the previous, traditional class, and students' attitude toward the mobile studio class, which we hoped told about the interest of students in the course and learning in general. The overall class grade was shifted toward higher end of the grade point, and the attendance increased with more students arriving early in the class. More survey results are detailed in the next section. 


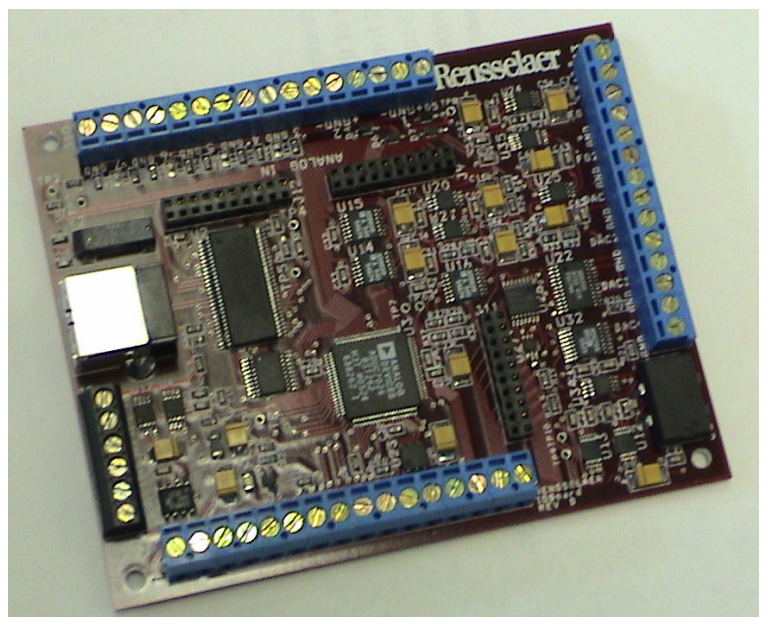

Fig.2. The Second Generation Instrumentation Board ("Red board")

\section{Assessment of the mobile studio experience}

We conducted three independent surveys over the year for the two courses. First two surveys were conducted by each instructor of the courses and the third one was conducted in collaboration with an evaluation specialist. The spring 2005 survey on Network Analysis aimed to measure mainly the acceptance of the students of the new mobile studio class, even though it also attempted to see how students actually experienced the experiential learning the mobile studio pedagogy tried to achieve. On the other hand, the fall 2005 survey on Electronics was the result of the instructor's observation of students' grades, stimulation, and attitude of the course. The last survey, conducted at the end of the fall 2005 semester, was designed by a specialist designed for more comprehensive look on the impact of Mobile Studio and conducted for the students who took Network Analysis or Electronics, or both. Each survey and its evaluation result follow.

\section{A. Survey on acceptance and learning experience of Mobile Studio}

There were 36 students in the Network Analysis class in spring 2005. We put the following five questions for the students to respond. First three questions were for the general acceptance measurement, the fourth one for the hands-one experience, and the last one for the problems they met and the improvement they wanted to see. The questionnaire was emailed to the students and 28 responded. We sorted the replies to each question and made out a few categories. Some replies were long and multi-faceted, and they were counted into multiple categories. These multi-category answers made the total number counts more than the responses in a few categories.

The questions and bulleted answers put inside box, with the number of replies on each category inside parentheses, and the analysis briefs are as follows.

(a) What did you like most of the mobile studio class?

- Hands-on experience by which circuit was heard and seen in practical sense. (17)

- Portability as a mobile laboratory with easiness in connection and wide display screen (14)

- Other (2) 
Over half the students liked the hands-on experience and practical sense of the class. About $40 \%$ of the students were impressed more on the technology enabled new learning environment. Overall $90 \%$ of the students were favorable to the mobile studio class.

(b) Do you like to have more mobile studio classes?

- Yes (28)

In this question, the answer was just one unanimous, "yes." Because of the new class, new technology, or any other reason, they liked the mobile studio class and they wanted more.

(c) In addition to Network Analysis, which course(s) would be most benefited by the mobile studio class?

- I don't know. I just took the first course in ECE! (4 )

- Electronics (15)

- Digital System (12)

- Signal Processing (4)

- Energy Conversion (1)

- Physics (Physics Department) (2)

Most could suggest the expansion of the benefit in Network Analysis and the experience of the mobile studio into other courses that they have yet to take. Electronics and Digital System courses received most votes in the suggestion.

(d) What did you learn most from the mobile studio class?

- Connection between Theory and Practical Application (22)

- Using new technology in measurement and circuit implementation (3)

- Appreciation Technology of Hardware and Software in Education (3)

The questionnaire wordings were poor but the intention of the question was clear: we wanted to measure the pedagogical proof of mobile studio. The response was very strong in the benefit of the mobile studio in the connection of theory and practical application. At the same time, students' appreciation of technology in teaching was also noted, which could be taken as acceptance of the mobile studio class.

(e) What improvement did you feel we have to make for better mobile studio class?

- I cannot think of any now (6)

- Allocation of more time (5)

- Bigger room - the classroom which was usually big enough for regular class was small for the mobile studio (4)

- More working practical modules for hands-on experience (1)

- Functional problem of I/O module and software (5)

- Enough number of systems so that each student has one, instead of sharing one with a few students. (7)

- Easier and faster setting up of the system and breadboard (5) 
There were many problems in the first semester of mobile studio. Hardware connection and occasional malfunction problems were persistent through the semester. With only 10 sets of Mobile Studio, accommodating 26 students made the class crowded around the mobile studio sets and not all students had equal access and made equal contribution. Also, the existing class time of one and half hours were usually short for theory explanation, circuit implementation, and testing and measurement using mobile studio. These problems were addressed for better arrangement and improvement for the next mobile studio class.

In summary, in the spring 2005 launch of mobile studio class in Network Analysis, amid problems and difficulties, students very favorably accepted the new learning environment, and experienced and benefited from the experiential learning phase of conceptualization to active experimentation.

\section{B. Observation of Student performance and Behavior under Mobile Studio}

Instructor's observation and analysis of fall 2005 mobile studio on Electronics course were directed to the performance and attitude of the students in the class compared with those of fall 2004 class. Most students in the fall 2005 class were already exposed to the mobile studio when they took Network Analysis in the previous semester. There were 42 students in the fall 2005 class; 32 students in fall 2004. The instructor of the course, who started to teach the course in fall 2004 semester, was so disappointed with the class especially in the grades and attendance that, while testing mobile studio in his second teaching of the course, he paid keen attention to the grade in homework and exams, attendance, and attitude of the students.

In the grade, we found dramatic improvement. The final grade, which in the last year showed rightskewed distribution, with A left-most and D at right-most, shifted to the left, with percentage of the student who made A or B doubled. In addition, the class average of homework and final exam scores improved by four and thirteen percentage points, respectively.

Class attendance improved in not only number of students in class but also their arrival pattern to the class: more students came to the class before class started, which was a big change for an 8:00 am class, and late arrivals were reduced. Also, changes in attitude and motivation were observed: more students visited the instructor for questions and further discussion of the class.

In summary, the mobile studio in Electronics in fall 2005 demonstrated its advantage in students' grade and behavior. They better performed and were more engaged and excited about the class.

\section{Overall Evaluation of Mobile Studio Class}

In December 2005, when the fall 2005 semester was over, we conducted another survey for the students who had experienced mobile studio class of Network Analysis or Electronics, or both, to assess the following three aspects: learning enhancement, stimulation and excitement of learning, and active engagement. In addition to these main components of experiential learning of mobile studio, the survey sought to conclude the student's acceptance of mobile studio. A total of 47 students completed an in-class survey. 
Students were asked to respond to the learning component questions with their level of agreement or disagreement, from "strong disagreement" to "strong agreement." The learning components questions were:
Student Learning
(a) Understanding of the lecture
(b) Ability to apply the theory
(c) Knowledge of the subject matter
(d) Attention to the lecture
(e) Interest in the subject matter
(f) Class attendance
(g) Motivation in class
(h) Participation in class
(i) Interaction with the instructor
(j) Interaction with other students

Using the scale below, please indicate your level of agreement or disagreement with the statements regarding the use of the Mobile Studio/Tablet PC in your course(s). (Check one response per item): Strongly Disagree, Disagree, Neutral, Agree, Strongly Agree.

I. Using the Mobile Studio/Tablet PC increased my:

The first three questions, (a) - (c), were for learning enhancement, and the next five questions, (d) (h), were directed for the enthusiasm and excitement of the class and learning. The last two questions, (i) and (j), were to see the engagement change in peer-to-peer and with instructor. In the analysis, we rated each response with a score in the range from 1 to 5 , score 5 for "strong agreement" and 1 for "strong disagreement."

Overall, the response was positive. Students recognized the increases, notably, in their: (a) ability to apply the theory $($ mean $=4.00$, std $=1.16)$, (b) knowledge of the subject matter $($ mean $=3.72$, std $=$ $1.09)$, and (c) interaction with other students in the course (mean $=4.15$, std $=1.00)$. The least appreciated, even tough still in the positive side, was the improvement in the class attendance. It is unclear if students were attending classes regularly therefore no stimulation affected this behavior, or the class was not exciting enough to encourage those who missed class occasionally to come to the class. Either interpretation, combined with the responses (d) through (e) and (g), would be enough to say that the mobile class played role in getting students attention to the class. The engagement experience in general was positive; however, the increase in interaction with instructor was much less than that with peers. The peer learning and engagement were the most favorable response of all.

The second part of survey was designed to assess students' acceptance of the mobile studio class. They were asked to select one answer from each question. The questions asked in part II and their choices were:

\section{Indicate your response:}

(a) Overall, how do you rate the potential of the Mobile Studio/tablet PC in terms of teaching and learning in the Department of Electrical and Computer Engineering? (very positive, somewhat 
positive, somewhat negative, very negative, don't know/no opinion)

(b) Overall, how do you rate the use of Mobile Studio/tablet PC in this particular course? (excellent, good, faire, poor)

(c) Would you like to see Mobile Studio/ tablet PCs integrated into your other courses within the department? (Definitely Yes, Maybe, Definitely No)

(d) How comfortable are you with using the Mobile Studio/tablet PC? (very comfortable, somewhat comfortable, somewhat uncomfortable, very uncomfortable)

The response showed that:

(a) $75.7 \%$ rated the potential of the Mobile Studio/tablet PC in teaching and learning as "very positive,"

(b) $51.1 \%$ rated the Mobile Studio in their course as "excellent,"

(c) $70.2 \%$ of the students "definitely" would like to see more Mobile Studio classes, and

(d) $59.6 \%$ felt "very comfortable" using the Mobile Studio/tablet PC.

The last part of the survey contained three questions to receive students' comments on the appreciation/use of the Mobile Studio, problems and difficulties, and other thought. As before, we sorted out the replies to each question and made out a few categories. The questions and bulleted answers put inside box, with the number of replies on each category inside parentheses, and the analysis briefs are as follows.

Part III: Please comment on the following questions.

(a) What were the most valuable attributes of the Mobile Studio for teaching and learning?

- The convenience of pen feature of tablet PC (1)

- hands-on environment and practical learning of theory ( 25)

- Instant simulation (5)

- Access to Internet and Information/material ( 7)

- Interaction with students/lecturer in the class (1 )

(b) What difficulties, if any, did you experience from the use of the Mobile Studio?

- None (12)

- Not enough time (3)

- Malfunction of Mobile Studio or its component (11)

- Wireless Network Problem ( 6)

- Not enough set of Mobile Studio/tablet PC (2)

- Familiarity with the Mobile Studio component (4)

(c) Provide any additional comments about the use of Mobile Studio for teaching and learning.

- More mobile studio (6)

- Enough Mobile Studio set For each student (1)

- More reliable Hardware/Software for Mobile Studio (1)

Analysis of these open questions reached at the same conclusion as the spring 2005 survey. To most students, the hands-on environment and practical learning of theory was most valuable experience, on which the mobile studio pedagogy was centered. Some appreciated the wireless access of the 
subject material of the class. The difficulties and problems were common: the interface board malfunction problem and not enough mobile studio sets. The time issue was not completely solved even with much longer time allocated in Electronics. Conclusively, students asked for more mobile studio classes in other courses.

\section{Summary of the Assessment}

From the series of surveys, we reached at the following conclusions. First, for the acceptance of the mobile studio class, students unanimously approved the new learning environment of mobile studio. Second, for the appealing of the mobile studio, students rated the hands-on experience and practical application of theory as the most valuable contribution of the mobile studio. The mobile studio stimulated peer-to-peer interaction, improved the attendance, made students come to the class early, and engaged students with instructor. Third, for learning enhancement, students felt that through the mobile studio class they could increase the important ability as engineering students in knowledge level of the subject as well as application of the knowledge to practice. Also, the class grade distribution in Electronics was shifted toward better grade.

The assessment supported the benefit of the mobile studio pedagogy, and it affirmed that the eminent benefit of the mobile studio was the experiential learning in the connection of theory and practical application. The survey revealed that students viewed the following as some of the most valuable attributes of the mobile studio learning: hands on environment, practical application of the subject matter, and lively environment of peer interaction and learning. Even with the problems and difficulties around hardware and software, students earned the most valuable learning experience in experiential environment.

\section{Conclusion}

This paper reported our experience with mobile studio in unifying two separated classes of lecture and lab in Electrical Engineering. We discussed, in particular, the hardware implementation by incorporating tablet PCs and instrumentation cards, embedding them into a mobile studio class. The paper also reported the assessment and evaluation of student responses in the acceptance of the new classroom environment and learning enhancement. The students unanimously approved the new learning environment of mobile studio and they rated the hands-on experience and practical application of theory as the most valuable contribution of the mobile studio. For learning enhancement, students felt that through the mobile studio class they could increase the important ability as engineering students in knowledge level of the subject as well as the application of knowledge into practice. The assessment supported the benefit of the mobile studio pedagogy, and it affirmed the benefit of the mobile studio in experiential learning of connecting theory and practical application. Even with the problems and difficulties around hardware and software, students earned the most valuable learning experience in experiential environment enabled by mobile studio. 


\section{References}

[1] Gary A. Gabriel and Richard M. Hein," Designing Spaces That Accommodate the Technologies That Are Transforming the Learning Environment," PKAL Volume IV: What works, what matters, what lasts 2004-present, Project Kaleidoscope.

[2] Don L. Millard, "Expanding the Benefits of Mobile Studio Classrooms" http://mobilestudio.rpi.edu/Project.aspx 2007

[3] Learning Pyramid. National Training Lab

[4] David Kolb, et al., Organizational Psychology: An Experiential Approach, Prentice-Hall, New Jersey, 1971.

[5] S. Jiusto and D. DiBiasio, "Experiential Learning Environments: Do They Prepare Our Students to be Self-Directed, Life-Long Learners?" Journal of Engineering Education, July 2006.

\section{Biographies}

Charles Kim received a Ph.D. degree in Electrical Engineering from Texas A\&M University in 1989. From 1990 to 1994 he was a post-doctoral research associate and, later, a research faculty member at Texas A\&M University. From 1994 to 1998, he was an assistant professor at the University of Suwon. Since 1999, he is with Department of Electrical Engineering at Howard University. Dr. Kim's research interests include PLC communication, embedded computing, Topological analysis of complex systems, and intelligent systems application. Dr. Kim is also active in application and assessment of technology in engineering education.

Mohamed Chouikha received a Ph.D. degree in Electrical Engineering from the University of Colorado in Boulder in 1988. Since 1988, he has been with Department of Electrical Engineering at Howard University. Since 2000, he has been serving as the Chair of the EE Department. Dr. Chouikha's research interests include Multimedia Signal Processing and Communications, Wireless Communications, and Home-networking. Dr. Chouika is the prime mover of the mobile studio inception and expansion at Howard University.

Veronica G. Thomas received a Ph.D. degree in Social Psychology from Howard University in 1982. She is currently a Professor within the Department of Human Development and Psychoeducational Studies and Senior Research Associate with the Capstone Institute, both at Howard University. Dr. Thomas' research interests include culturally responsive evaluations and the educational and socioemotional outcomes of students of color. Dr. Thomas has collaborated with the Department of Electrical Engineering in planning and implementing evaluation studies. 